\title{
Glycogen storage disease due to LAMP-2 deficiency
}

INSERM

\section{Source}

INSERM. (1999). Orphanet: an online rare disease and orphan drug data base. Glycogen storage disease due to LAMP-2 deficiency. ORPHA:34587

Glycogen storage disease due to LAMP-2 (Lysosomal-Associated Membrane Protein 2) deficiency is a lysosomal glycogen storage disease characterised by severe cardiomyopathy and variable degrees of muscle weakness, frequently associated with intellectual deficit. 